\title{
Dexamethasone differentiates NG108-15 cells through cyclooxygenase 1 induction
}

\author{
Hyeon Soo Kim ${ }^{1}$, Minseok Song', \\ Euikyung Kim ${ }^{1}$, Sung Ho Ryu ${ }^{1}$ \\ and Pann-Ghill Suh ${ }^{1,2}$ \\ ${ }^{1}$ Department of Life Science \\ Division of Molecular and Life Science \\ Pohang University of Science and Technology \\ San 31 Hyoja-dong, Nam-gu, Pohang \\ Kyungbuk 790-784, Korea \\ ${ }^{2}$ Corresponding author: Tel, 82-54-279-2293; \\ Fax, 82-54-279-2199; E-mail, pgs@postech.ac.kr
}

Accepted 21 May 2003

Abbreviations: COX, cyclooxygenase; db cAMP, dibutryl cyclic AMP

\begin{abstract}
Cyclooxygenase (COX) is a key enzyme in the conversion of arachidonic acid into prostanoids which participate in various cellular functions including apoptosis, mitogenesis, inflammation, immune modulation and differentiation. Moreover, the synthetic glucocorticoid, dexamethasone has immune modulating and anti-inflammatory effects in vivo. Recently, dexamethasone was found to enhance retinoic acid-induced neuronal differentiation. In this study, we investigated the mechanisms of dexamethasone-mediated neuronal differentiation. Immunoblotting and morphological analysis demonstrated that dexamethasone induced neuronal differentiation through COX 1 induction. This phenomenon was inhibited by indomethacin, a COX inhibitor. In addition, the addition of exogenous prostaglandin E2 (PGE2), a substance produced by the COX-mediated pathway, triggered neurite outgrowth of cells treated with COX inhibitor. Taken together, COX 1 appears to play an important role in dexamethasone-mediated neuronal differentiation.
\end{abstract}

Keywords: cell differentiation; dexamethasone; neurites; prostaglandin-endoperoxide synthase; prostaglandins indomethacin

\section{Introduction}

Neuroblastoma is a childhood tumor of the sympathetic nervous system. Although the majority of neuroblastomas are aggressive and are associated with a poor clinical outcome, the most favorable subset of this tumor may differentiate or regress spontaneously due to apoptosis. The observation that neuroblastoma may occasionally regress by differentiation has generated considerable interest in the nature of the biologic processes involved. Moreover, the dysregulation of neuronal differentiation leads to disorder associated with degeneration such as Alzheimer disease. Thus differentiation is necessary for the maintenance of neuronal functional integrity.

COX is implicated in many cellular functions, including proliferation and differentiation. Two distinct COX isoforms have been identified. Although the mechanisms of the COX 2 mediated pathway are well defined, the COX 1 mediated pathway is relatively unknown. COX 1 mRNA is barely detectable in the brains of fetal rats, but increases during development and reaches its highest levels in adult animals (Kawasaki et al., 1993; Kaufmann et al., 1996; Ma et al., 1998; O'Banion et al., 1999). This progressive increase seems to be related with the modulation of developmental or differentiation responses. Compared with COX 2, much less is known about the expression and function of COX 1 in neuronal cells. One group reported that COX 1 was up-regulated in the phechromocytoma cell line PC 12 after the induction of differentiation by nerve growth factor (Xie et al., 1996; Kaplan et al., 1997; Reddy et al., 1997; Goppelt et al., 2000). However, the circumstances under which dexamethasone modulates neuronal differentiation and the mechanisms involved remain poorly understood.

Prostaglandin is the major enzymatic product of the COX mediated pathway and a key proinflammatory mediator. Among the various known prostanoids, PGE2 is known to be involved in differentiation. It has been reported that $\mathrm{PGE} 2$ affects the dendrite-promoted differentiation of naive $T$ cells to Th1 response in the basal state, without affecting chemokine receptor expression on dendrite cells (Lee et al., 2002). However, it is not known whether such differentiation occurs in neuron or what mechanisms are involved.

Dexamethasone, a synthetic glucocorticoid, is known to have anti-inflammatory and immune suppressive effects. However, although dexamethasone is known to enhance retinoic acid-induced differentiation, the 
mechanisms of dexamethasone-mediated neuronal differentiation remain largely unknown.

NG108-15 cholinergic neuroblastoma cell have been widely used in differentiation studies (Klee and Nirenberg et al., 1974; Hamprecht et al., 1977). NG108-15 cells show neuritic growth in the presence of dibutryl cyclic AMP, which results in the development of neuronal morphology (Nirenberg et al., 1983). Although physiological, pharmacological and biochemical studies have characterized the neuronal functions and features of differentiated NG108-15 cells, the molecular mechanisms underlying this differentiation have not been explained completely.

In the current study we investigated the effects of dexamethasone on neuronal differentiation. Our results reveal that COX 1 is required for dexamethasoneinduced NG108-15 differentiation. We also found that indomethacine inhibits dexamethasone-induced neuronal differentiation. Moreover, exogenous PGE2 triggered the differentiation of neuron cells treated with indomethacine. In summary, this study demonstrates that COX 1 plays an important role in neuronal differentiation.

\section{Materials and Methods}

\section{Materials}

NG108-15 cells (a mouse neuroblastoma-rat glioma hybrid cell line) were used. Dexamethasone, $d b \mathrm{cAMP}$, indomethacin and PGE2 were purchased from Sigma (Deisenhofen, Germany). Stock solutions of dexamethasone and PGE2 were prepared in DMSO and ethanol, respectively. Appropriate solvent controls were used throughout the study.

\section{Cell culture and treatment}

NG108-15 cells were cultured in Dulbecco's modified Eagle's medium (DMEM) (Gibco BRL, Gaithersburg, MD) containing 10\% FBS, $2 \%$ HAT supplement (10 $\mathrm{mM}$ hypoxanthine, $40 \mathrm{mM}$ aminopterine, $1.6 \mathrm{mM}$ thymidine; Gibco/Life Technologies, Eggenstein, Germany), $2 \mathrm{mM}$ L-glutamine, $4.5 \mathrm{~g} / \mathrm{l}$ glucose and 100 $\mathrm{U} / \mathrm{mM}$ streptomycin. For the experiment cells were seeded at a density of $1.5 \times 10^{5}$ cells $/ \mathrm{ml}$ in $6-\mathrm{cm}$ diameter Petri dishes in medium supplemented with $10 \%$ FBS. NG108-15 cells were cultured as monolayers in plastic flasks, containing DMEM containing high concentrations of glucose and supplemented with $10 \mathrm{mM}$ hypoxanthine, $0.1 \mathrm{mM}$ aminopterin, $1.6 \mathrm{mM}$ thymidine and $10 \% \mathrm{FBS}$, in a humidified with $10 \%$ $\mathrm{CO}_{2}$ in air incubator at $37^{\circ} \mathrm{C}$. To induce neuronal differentiation, $20 \mu \mathrm{M}$ dibutyryl (db) cAMP and $2 \mu \mathrm{M}$ dexamethasone were added to the culture medium and cells were then cultured for 1 day. The cells were further cultured in medium containing 1\% FBS in the presence or absence of dexamethasone. Indomethacin was co-treated with dexamethasone to inhibit COX activity when required.

\section{Western blotting}

After stimulation, the cells were washed with PBS and then lysis buffer $(20 \mathrm{mM}$ Tris- $\mathrm{HCl}(\mathrm{pH} 7.4), 150 \mathrm{mM}$ $\mathrm{NaCl}, 1 \%$ Triton X-100, $0.1 \mathrm{mM}$ PMSF, $5 \mu \mathrm{g} / \mathrm{ml}$ aprotinin, and $1 \mu \mathrm{M}$ pepstatin). The protein concentration was determined using the Bio-Rad protein assay. For Western blot analysis, $20 \mu \mathrm{g}$ of protein was separated by SDS-PAGE ( $10 \%$ polyacrylamide), transferred onto nitrocellulose membrane and probed with specific antibodies. The antibody incubation directed against COX 1 was performed. To correct for equal loading, the membrane was blotted with $\alpha$-actin antibody to produce a molecular mass of about $43 \mathrm{kDa}$.

\section{Morphological analysis}

To determine the effects of dexamethasone on differentiation, we observed its effect on the morphology of NG108-15 cells. Neurite outgrowth was measured after treating with dexamethasone, $\mathrm{db}$ cAMP and prostaglandin E2. Cells were plated at a relatively low density of $3 \times 10^{4}$ cells per well in 6 well plates to minimize neurite contact, incubated for $24 \mathrm{~h}$ and the medium was then changed to $1 \%$ FBS containing DMEM. The cells were treated with each agent and grown in dexamethasone and $\mathrm{db}$ cAMP and PGE2 for $24 \mathrm{~h}$. They were then photographed under a Zeiss Axiovert LSM510 inverted microscope fitted with phasecontrast optics. The number of branches and the neurite lengths were measured using an image analysis program.

\section{Results}

\section{Effect of dexamethasone on NG108-15 differentiation}

To examine the effects of dexamethasone on neuronal differentiation, we monitored NG108-15 cells morphology after dexamethasone treatment. Differentiation was defined as dendrite growth exceeding twice the cell body diameter. After incubating for $24 \mathrm{~h}$, dexamethasone $(2 \mu \mathrm{M})$ was found to dramatically induce neurite outgrowth (Figure 1A). db cAMP, a well known neuronal differentiating agent, was used as a positive control (Figure 1A). The number of branch points and the lengths of neurites were measured using a confocal microscope equipped with image processing software (LSM510, Zeiss). Analysis showed that the neurite lengths and branch points increased by 5 - and 
2-fold in dexamethasone-treated cells, respectively (Figure 1B). To confirm the ability of dexamethasone to differentiate the neuron cells, we investigated the expression level of Tau, well known neuronal marker, after dexamethasone treatment. Dexamethasone as well as db cAMP could increase the level of Tau (Figure 1C). Increase of Tau after dexamethasone was time dependent (Figure 1D). These results demons-

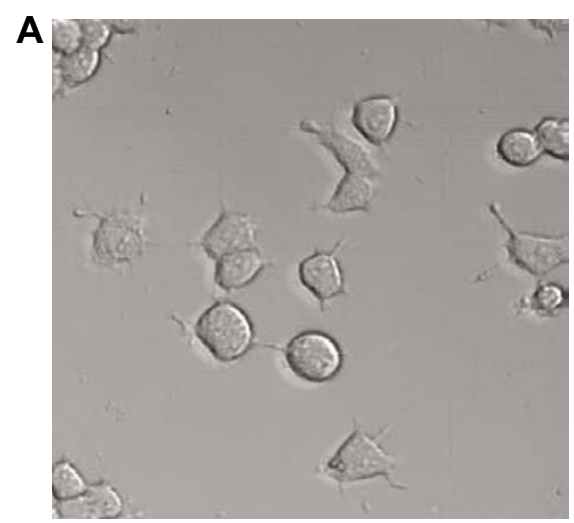

Control

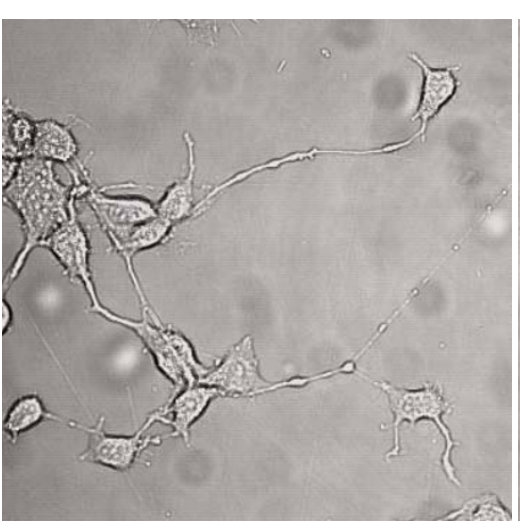

Dexa

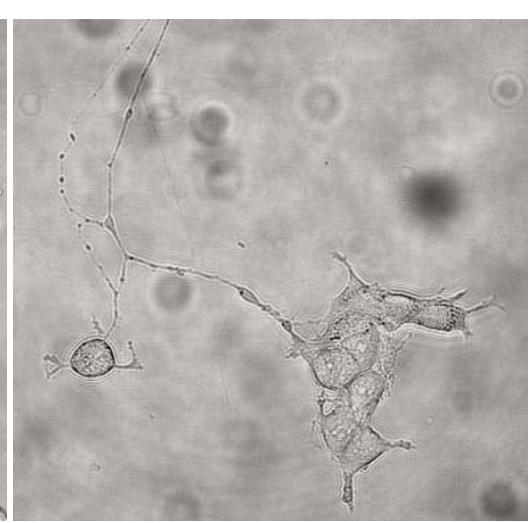

db cAMP
B

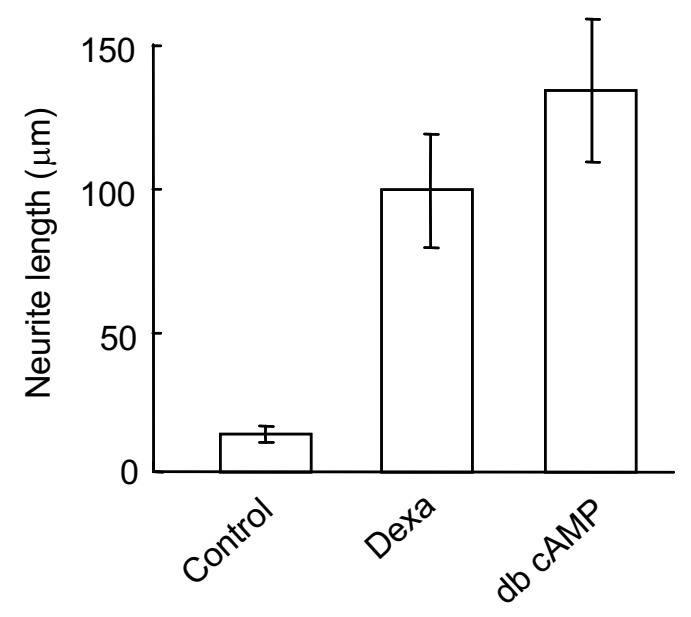

C

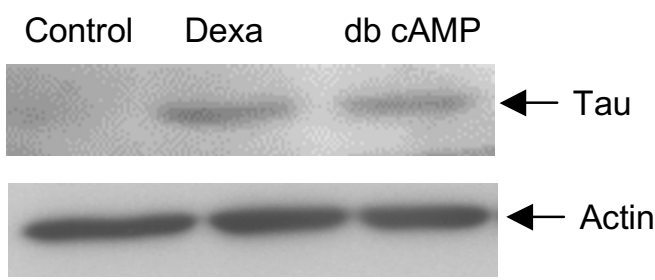

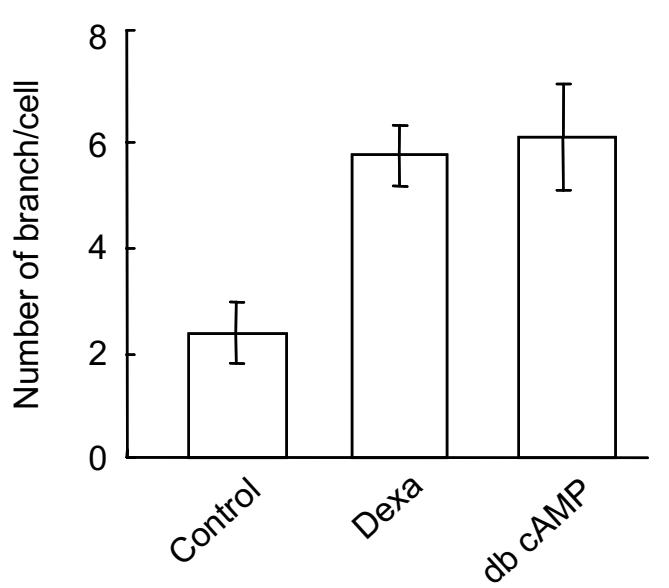

D

Dexa
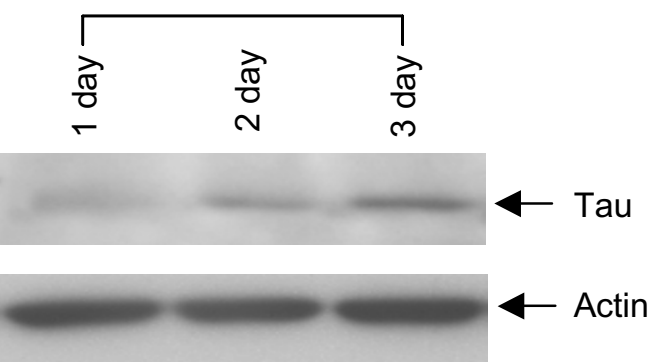

Figure 1. Differentiation of NG108-15 cells by dexamethasone. NG108-15 cells were initially grown 10\% FBS containing DMEM media. After changing to $1 \%$ serum condition, the cells were treated with dexamethasone $(2 \mu \mathrm{M})$ and db cAMP $(20 \mu \mathrm{M})$ for $24 \mathrm{~h}$. A, Morphology was monitored by transmission image of confocal microscopy (Zeiss LSM510, objective $\times 20$ ). B, Quantitative analysis was performed of the effects of dexamethasone and $\mathrm{db}$ CAMP on neurite length and the number of branch points. Transmission images were processed using an image analysis program. Representative pictures of the cells are shown and the results of three independent experiments are summarized. C, Cells were lysed after treatment of dexamethasone and $\mathrm{db}$ cAMP and $20 \mu \mathrm{g}$ of the total lysates were electrophoresed in $10 \%$ SDS-PAGE gels, transferred to nitrocellulose and immunoblotted with anti-Tau antibody. D, Cells were lysed after treatment of dexamethasone for the indicated times and 20 $\mu \mathrm{g}$ of the total lysates were electrophoresed in 10\% SDS-PAGE gels, transferred to nitrocellulose and immunoblotted with anti-Tau antibody. Dexa represents dexamethasone. 
trate that dexamethasone induces NG108-15 cell differentiation.

\section{Effect of dexamethasone on COX 1 expression in NG108-15 cells}

To determine the nature of mechanism involved in dexamethasone-induced neuronal differentiation, we examined the COX 1 expression after dexamethasone treatment. Currently, though the role of COX-mediated pathway in differentiation has been studied, many questions remain unanswered. We hypothesized that dexamethasone mediated neuronal differentiation through the COX-mediated pathway. To confirm this we investigated COX expression in NG108-15 cells after dexamethasone treatment. Cell lysates were analyzed by SDS-PAGE followed by transfer to nitrocellulose membrane and immunoblotted with anti-COX 1 antibody. The results obtained showed that dexamethasone induced more strongly the level of COX-1 than $\mathrm{db}$ cAMP (Figure $2 \mathrm{~A}$ ). Moreover, dexamethasone increased COX-1 expression in a time dependent manner (Figure 2B). However, COX 2 was not induced in NG108-15 cells by dexamethasone (Figure 2C). A control blot of $\alpha$-actin in the total cell lysates showed no change under the same conditions. These results suggest that COX 1 induction is involved in dexamethasone-mediated NG108-15 cell differentiation.

\section{Effect of dexamethasone on COX 1 expression} in HN33 hippocampal cells and $\cos 7$ cells

To examine the cellular specificity of $\operatorname{COX} 1$ induction, we used HN33, another hippocampal neuron cell line. Although HN33 cells are known to express glucocorticoid receptor, dexamethasone did not induce COX 1 in these cells (Figure 3A). Basal COX 1 level was high, but $\operatorname{COX} 1$ was not further increased by dexamethasone (Figure 3B). A control blot of the $\alpha$ actin in total cell lysates showed no change under the same conditions. To investigate the relationship between differentiation and COX 1 expression, we monitored cell morphology after dexamethasone treatment. Dexamethasone did not trigger HN33 cell differentiation. To more consolidate the cellular specificity, we investigated the effect of dexamethasone on non-neuronal $\cos 7$ cells. As the same as HN33 cells, dexamethasone neither differentiated COS 7 cells nor induced COX-1. These results imply that COX 1 induction by dexamethasone is NG108-15 neuroblastoma cell specific and that $\operatorname{COX} 1$ is required for dexamethasone-mediated neuronal differentiation.

\section{Effect of indomethacin on dexamethasone- mediated differentiation}

To confirm the role of COX 1 in dexamethasone-mediated differentiation, COX was inhibited with indome-
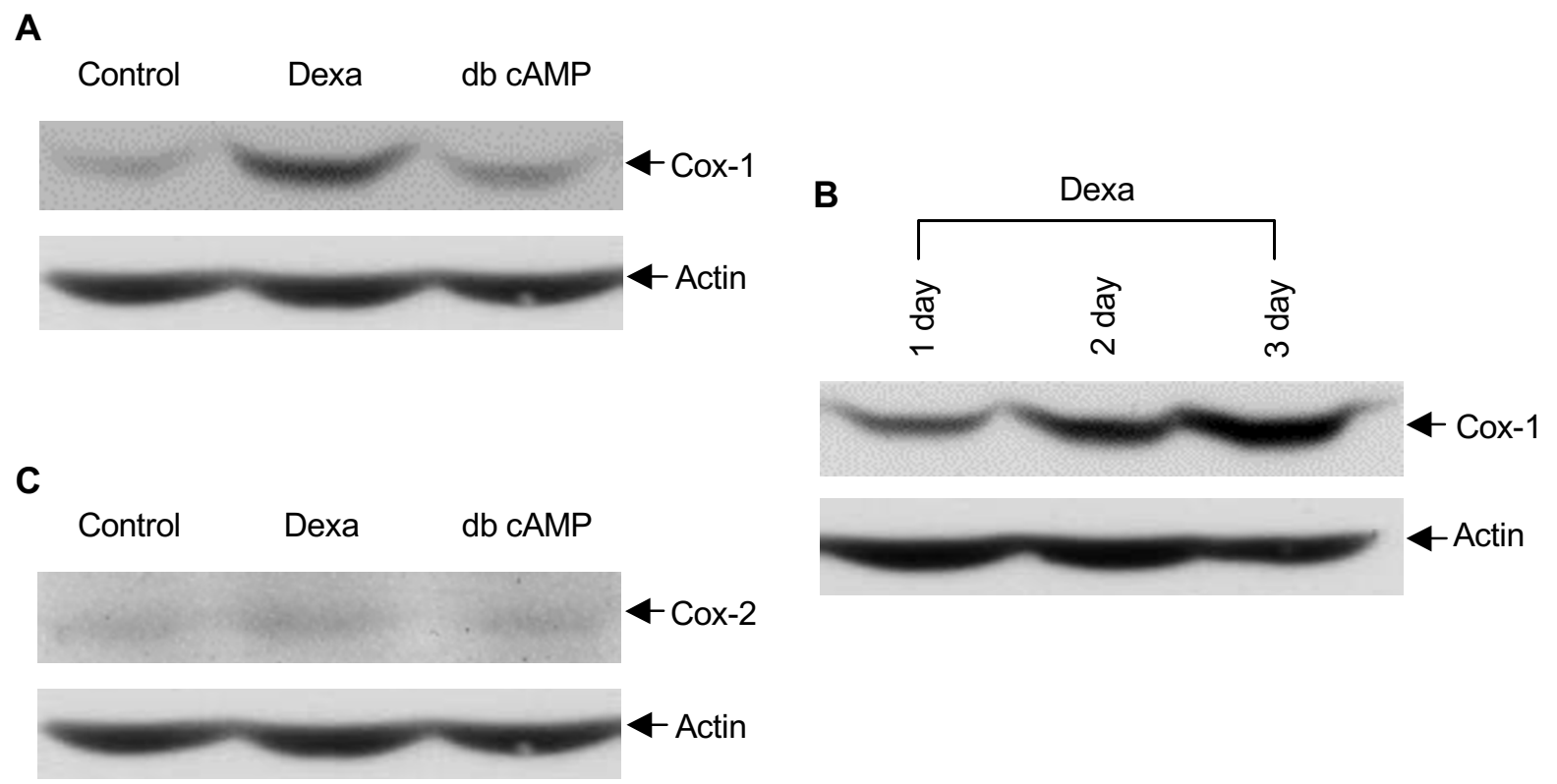

Figure 2. Induction of COX 1 by dexamethasone. NG108-15 cells were grown in $10 \%$ FBS containing DMEM media. After changing to $1 \%$ serum condition, cells were treated with dexamethasone $(2 \mu \mathrm{M})$ and $\mathrm{db}$ cAMP $(20 \mu \mathrm{M})$ for $24 \mathrm{~h}$. A, Cells were lysed and $20 \mu \mathrm{g}$ of the total lysates were electrophoresed in 10\% SDS-PAGE gels, transferred to nitrocellulose and immunoblotted with anti-COX 1 antibody. To control for equal loading, blots were incubated with $\alpha$-actin antibody. B, Cells were cultured for various times. Cell lysates were prepared and blotted with anti-COX 1 antibody. C. Cells were lysed and $20 \mu \mathrm{g}$ of total lysates were electrophoresed in 10\% SDS-PAGE gels, transferred to nitrocellulose and blotted with anti-COX 2 antibody. 
A

C

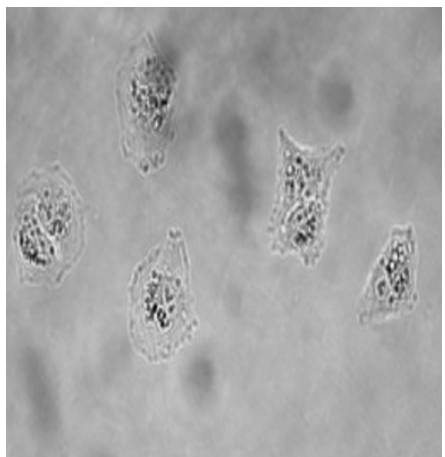

Dexa
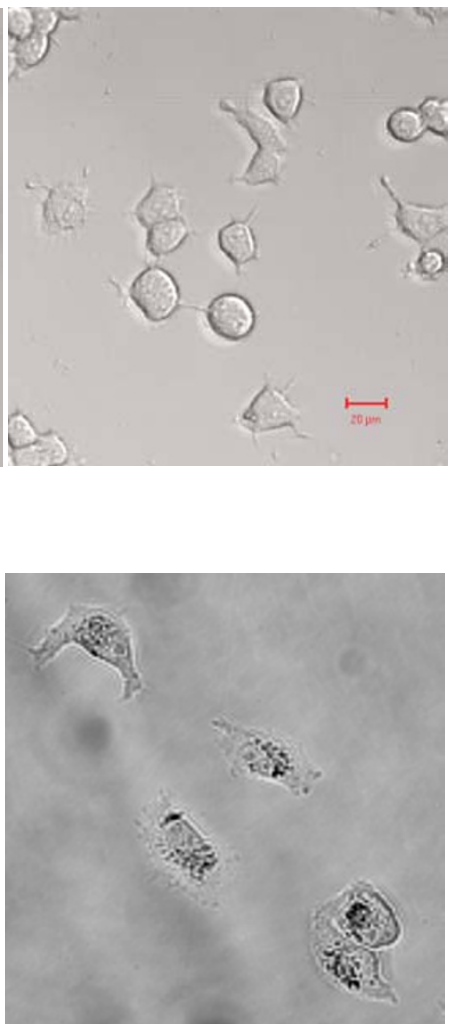

D

B

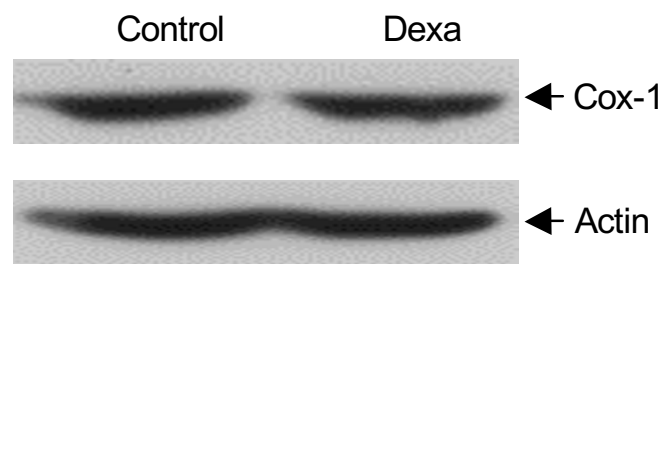

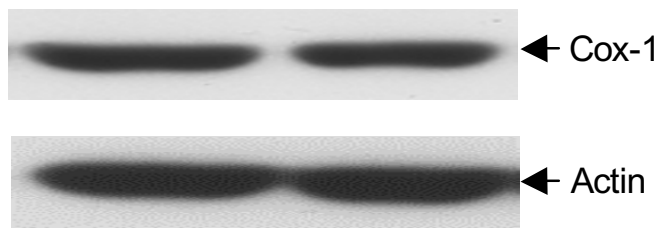

Figure 3. Effect of dexamethasone on the differentiation of HN33 hippocampal cells and COS 7 cells. A, HN33 cells were grown in 10\% FBS containing DMEM media. After changing to $1 \%$ serum condition, cells were treated with dexamethasone $(2 \mu \mathrm{M})$ for $24 \mathrm{~h}$. Cellular morphology was then monitored using an image analysis program. B, Cells were lysed and $20 \mu \mathrm{g}$ of the total lysates was electrophoresed in 10\% SDS-PAGE gels, transferred to nitrocellulose and blotted with anti-COX 1 antibody. To control for equal loading, blots were incubated with $\alpha$-actin antibody. $\mathrm{C}$, COS 7 cells were grown in 10\% FBS containing DMEM media. After changing to $1 \%$ serum condition, cells were treated with dexamethasone $(2 \mu \mathrm{M})$ for $24 \mathrm{~h}$. Cellular morphology was then monitored using an image analysis program. D, Cells were lysed and $20 \mu \mathrm{g}$ of the total lysates was electrophoresed in 10\% SDS-PAGE gels, transferred to nitrocellulose and blotted with anti-COX 1 antibody.

thacin. Accordingly, indomethacin $(2 \mu \mathrm{M})$ was treated $30 \mathrm{~min}$ prior to dexamethasone and co-incubated with dexamethasone for $24 \mathrm{~h}$. No increase of neurite length and branch points numbers were observed (Figure $4 A)$. This result implied that COX activity induced by dexamethasone was required for NG108-15 differentiation. To prove the involvement of COX 1 in dexamethasone-induced differentiation, we added exogenous PGE2, which is a major product of COX-mediated pathway. After co-treating with indomethacin and dexamethasone for $24 \mathrm{~h}, \mathrm{PGE} 2$ was added and we found that PGE2 triggered the differentiation of NG108- 15 cells co-treated with dexamethasone and indomethacin (Figure 4A). These results supported our hypothesis that dexamethasone differentiated NG10815 cells through COX-1 induction. Quantitative analysis showed that indomethacin inhibited increases in neurite length and branch points numbers triggered by dexamethasone (Figure 4B). In addition, exogenous PGE2 increased the length of neurite and the number of branch points by 5- and 2-fold in cells treated with indomethacin, respectively. Western blot analysis also revealed that exogenous PGE 2 induced the COX-1 level (Figure 4C). These results suggest that dexamethasone triggers the differentiation of NG108-15 through $\operatorname{COX} 1$.

\section{Discussion}

The present work shows that dexamethasone modulates COX 1 in neurons. Many cellular functions, including proliferation and differentiation, are implicated in the COX mediated pathway. The inducible COX 2 isoform has been linked primarily to inflammatory processes, whereas the expression of COX 1 is confined to specific physiological functions. Several reports indicate that $\operatorname{COX} 1$ also might be induced during differentiation in the hematopoietic cell lineage (Smith et al., 1993; Torsten et al., 1993; Murakami et al., 1994; 
A

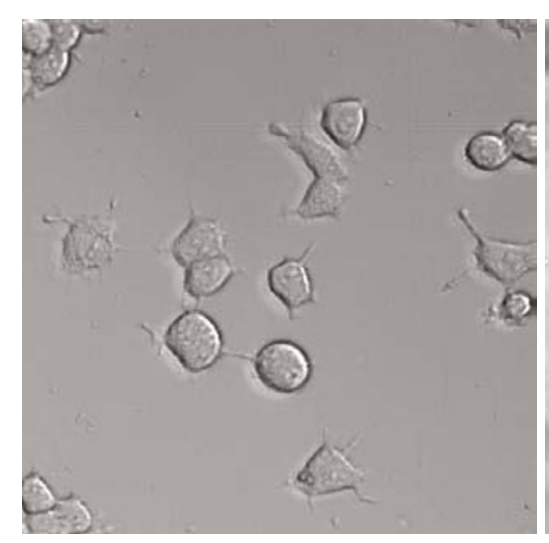

Dexa/Indo

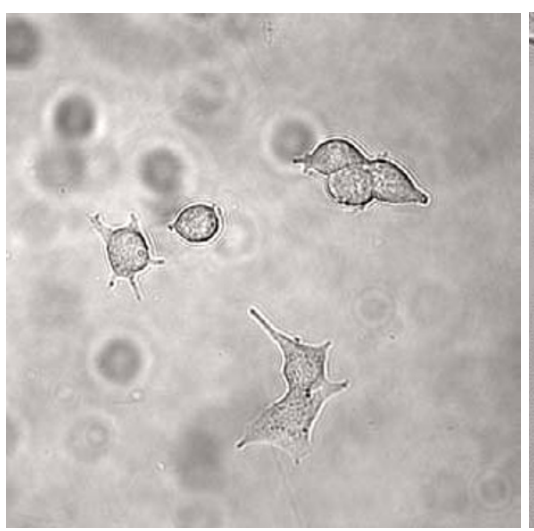

Dexa/Indo/PGE2

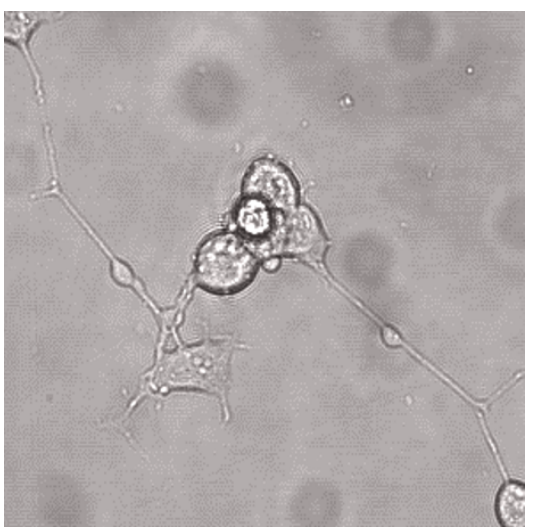

B

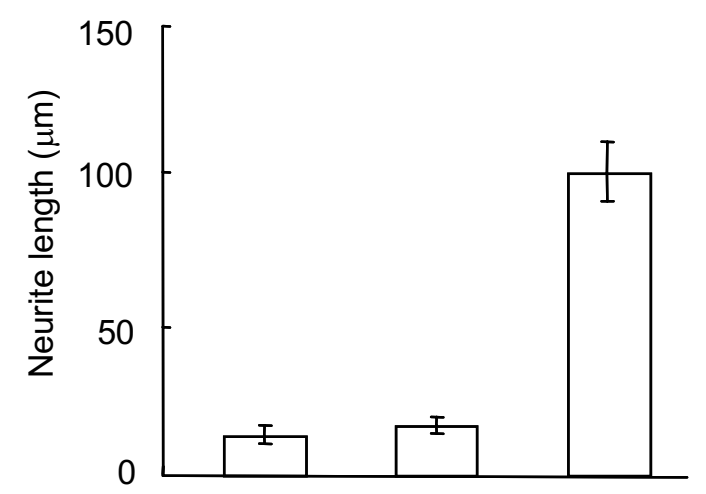

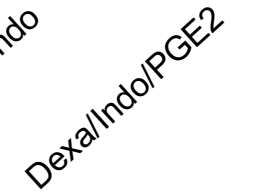
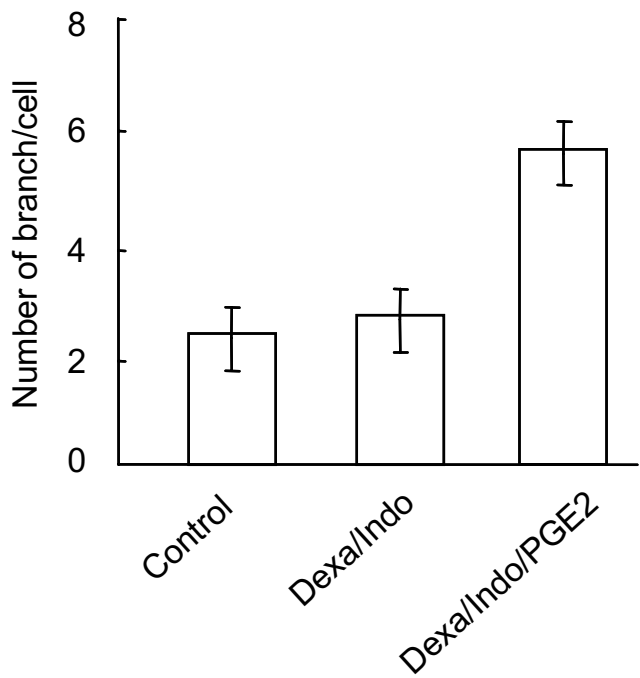

C

Control

PGE2

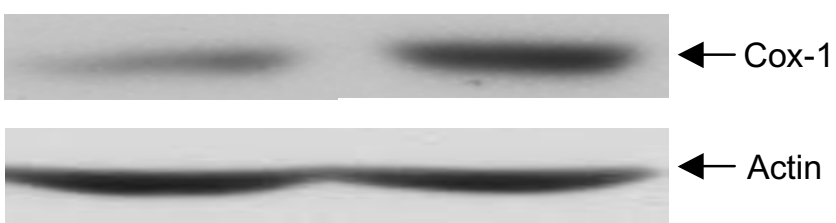

Figure 4. Inhibition of differentiation by COX inhibitor. NG108-15 cells were grown in 10\% FBS containing DMEM media. After changing to $1 \%$ serum condition, cells were co-treated with dexamethasone $(2 \mu \mathrm{M})$ and indomethacin $(2 \mu \mathrm{M})$ for $24 \mathrm{~h}$, exogenous PGE2 $(2 \mu \mathrm{M})$ was then added incubation continued for $24 \mathrm{~h}$. A, Cellular morphology was monitored by transmission image of confocal microscopy (Zeiss LSM510, objective $\times 20)$. B, Results of the quantitative analysis of the effect of dexamethasone, indomethacine and PGE2 on neurite length and branch points. Cellular morphology was monitored by transmission image of confocal microscopy. Indo represents indomethacin. C, Cells were lysed after PGE2 treatment. $20 \mu \mathrm{g}$ of the total lysates was electrophoresed in 10\% SDS-PAGE gels, transferred to nitrocellulose and blotted with anti-COX 1 antibody.

Natsuo et al., 1997). One group reported upon phenotype with COX 1 and COX 2 deficiency in skin and found that a deficiency of either $\operatorname{COX} 1$ or $\operatorname{cox} 2$ altered epidermal differentiation (Howard et al., 2002). These results suggest that $\operatorname{COX} 1$ or 2 may have some role in the differentiation of keratinocytes. On the other hand, another group reported that Id (inhi- bitor of differentiation) might negatively regulate the tissue specific expression of differentiation factor (Chil et al., 2002). However, the mechanisms establishing the neurite outgrowth in the CNS remain extensively unknown. Thus many questions about how they are regulated in neuronal differentiation remain unclear. The present study suggests that COX 1 is induced 
in neuron cells by dexamethasone and that it has an important role in neuronal differentiation. Although another hippocampal neuronal cell line, HN33, is also known to express glucocorticoid receptors, this cell line showed neither COX 1 expression nor differentiation after dexamethasone treatment. These results imply that COX 1-mediated neuronal differentiation can be cell line specific.

Though PGE2 is a dominant form of prostanoid, which is synthesized by the COX mediated pathway, various other prostanoids are also synthesized. In our study, exogenous PGE2 triggered neurite outgrowth in NG108-15 cells treated with COX inhibitor. However, we did not examine the effects of other prostanoids on neuronal differentiation, thus we cannot rule out the possibility that differentiation is also triggered by other prostanoids. In addition, exogenous PGE2 induced COX 1 expression and the differentiation of NG108-15. These results imply that COX 1 induction may result from the differentiation itself or that COX 1 plays an important role in maintaining the differentiation status.

One group reported that neural cell adhesion molecule (NCAM) promoted the differentiation of hippocampal precursor cells to a neuronal lineage (Shin et al., 2002). In the current study, we found that COX 1 plays an important role in neuronal differentiation. These results suggested that several factors might be responsible for neuronal differentiation. To better understand the mechanism of neuronal differentiation, more study is needed to identify other differentiationrelated factors in neuron cells. In addition, we believe that such further studies should concentrate on defining the mechanisms of COX 1 induction and on fine-tuning our understanding of the role of $\operatorname{COX} 1$ in neuronal differentiation.

\section{Acknowledgement}

This work was supported by a grant from the Korea Science and Engineering Foundation (KOSEF 98-040102).

\section{References}

Ghil SH, Jeon YJ, Suh-Kim HY. Inhibition of BETA2/NeuroD by Id2. Exp Mol Med 2002;34:367-73

Goppelt-Strube M, Wiedemann T, Heusinger-Ribeiro J, Vucadinovic M, Rehm M, Prols F. COX-2 and osteopontin in cocultured platelets and mesangial cell: role of glucocorticoid. Kidney Int 2000;5796:2229-38

Hamprecht B. Structural, electrophysiological, biochemical, and pharmacological properties of neuroblastoma-glioma cell hybrids in cell culture. Int Rev Cytol 1977;49:99-107

Howard FT, Charles DL, Jackie A, Christopher AL, Judson
S, Alisha S, David BD, Eleanor GR, Scott GM, Robert CS, Robert L. Deficiency of either cyclooxygenase-1 or 2 alters epidermal differentiation and reduces mouse skin tumorigenesis. Cancer Res 2002;62:3395-401

Kaplan MD, Olschowka JA, O'Banion MK. Cyclooxygenase1 behaves as a delayed response gene in PC12 cells differentiated by nerve growth factor. J Biol Chem 1997;272: 18534-7

Kaufmann WE, Worley PF, Pegg J, Bremer M, Isakson P. COX-2, a synaptically induced enzyme, is expressed by excitatory neurons at postsynaptic sites in rat cerebral cortex. Proc Natl Acad Sci USA 1996;93:2317-21

Kawasaki M, Yoshihara Y, Yamaji M, Watanabe Y. Expression of prostaglandin endoperoxide synthase in rat brain. Brain Res Mol Brain Res 1993;19:39-46

Klee WA, Nirenberg M. A neuroblastoma times glioma hybrid cell line with morphine receptors. Proc Natl Acad Sci USA $1974 ; 71: 3474-7$

Lee JJ, Masao T, Shinichi H, Yoshiko I, Yukie H, Ryuji T, Yoshinobu K, Masayuki K, Atsushi M, Shin M, Hiroyuki K, Akihiro S, Yuji H, Yoshinori I, Hiro W, Yoichi T, Hwang TJ, Kim HJ, Tadao K. The role of PGE2 in the differentiation of dendritic cells: How do dendritic cells influence T-cell polarization and chemokine receptor expression? Stem Cell 2002;20:448-59

Ma W, Pancrazio JJ, Coulombe M, Dumm J, Sathanoori R, Barker JL, Kowtha VC, Stenger DA, Hickman JJ. Neuronal and glial epitopes and transmitter-synthesizing enzymes appear in parallel with membrane excitability during neuroblastoma $x$ glioma hybrid differentiation. Brain Res Dev Brain Res 1998;106:155-68

Murakami M, Matsumoto R, Austen KF, Arm JP. Prostaglandin endoperoxide synthase- 1 and 2 couple to different transmembrane stimuli to generate prostaglandin D2 in mouse bone marrow-derived mast cells. J Biol Chem 1994; 269:22269-75

Natsuo Ueda Rieko Yamashita, Shozo Yamamoto, Kazunori Ishimura. Induction of cyclooxygenase-1 in a human megakaryoblastic cell line (CMK) differentiated by phorbol ester. Biochem Biophys Acta 1996;1344:103-10

Nirenberg M, Wilson SP, Higashida $H$, Rotter A, Kreuger K, Busis N, Ray R, Kenimer J, Alder M, Fukui H. Synapse formation by neuroblastoma hybrid cells. Cold Spring Harb Symp Quant Biol 1983:48:707-15

O'Banion MK. Cyclooxygenase-2: molecular biology, pharmacology, and neurobiology. Crit Rev Neurobiol 1999;13:4582

Reddy ST, Herschman HR. Prostaglandin synthase-1 and prostaglandin synthase-2 are coupled to distinct phospholipase for the generation of prostaglandin D2 in activated mast cells. J Biol Chem 1997;272:3231-7

Shin MH, Lee EG, Lee SH, Lee YS, Son H. Neural cell adhesion molecule (NCAM) promotes the differentiation of hippocampal precursor cells to a neuronal lineage, especially to a glutamatergic neural cell type. Exp Mol Med 2002;34: 401-10

Smith CJ, Morrow JD, Roberts LJ, Marnett LJ. Differentiation 
of monocytoid THP-1 cells with phorbol ester induces expression of prostaglandin endoperoxide synthase1 (COX-1). Biochem Biophys Res Commun 1993;192:787-93

Torsten Hoff, David Dewitt, Volkhard Kaever, Klaus Resch, Margarete Goppelt-Strube. Differentiation-associated expres- sion of prostaglandin $\mathrm{G} / \mathrm{H}$ synthase in monocytic cells. FEBS Lett 1993;320:38-42

Xie W, Herschman HR. Transcriptional regulation of prostaglandin synthase 2 gene expression by platelet-derived growth factor and serum. J Biol Chem 1996;272:31742-8 